\title{
Study on the Relationship Between the Economic Growth and Carbon Emission in Heilongjiang Province
}

\author{
YANG Xu ${ }^{1,2, a^{*}}$, LUO Pan ${ }^{1, b}, R U Y^{1, c}$, LI DongLiang ${ }^{1, d}$, FAN DaSha ${ }^{1, e}$ and XU \\ Yang ${ }^{1, \mathrm{f}}$
}

1 College of Geographical Science, Harbin Normal University, Key Laboratory of Remote Sensing Monitoring of Geographic Environment, College of Heilongjiang Province, Harbin 150025, China

2Antai College of Economics \& Management, Shanghai Jiao Tong University, Shanghai 200030, China

ayangxu2005gd@163.com, b 1228072128@qq.com , c 251825159@qq.com,d 553522324@qq.com, e 824619786@qq.com, f841472271@qq.com

\begin{abstract}
Keywords: Heilongjiang province; economic growth; carbon emission; relationship
Abstract. This paper investigates the dynamic relationship between the economic growth and carbon emission in Heilongjiang province based on the data from 1990 to 2011. The results show that the carbon dioxide emission has been still increasing with economic growth since 1990. The paper researches on the relationship between the per capita GDP and the per capita carbon emission during 1990 to 2011 by using the Environmental Kuznets Curve (EKC) equation. The results display that the carbon emission in Heilongjiang accords with the inverted U-shaped of the Environmental Kuznets Curve (EKC), and now it doesn't reach the position of the inflection point. Only accelerating technological innovation, readjusting industrial structure, developing the feasible measures for energy saving, the inflection point as soon as possible was got through. The sustainable development of low-carbon economy will be realized in Heilongjiang province.
\end{abstract}

\section{Introduction}

With the sustainable growth of human social population, the rapid development of the industrialization and urbanization, the ecological environment is continuous deterioration, especially global warming has been a serious threat to human sustainable development. it is a great challenge for global to facing the climate change. Since the founding of New China, the Chinese economy has maintained rapid growth. The average annual growth rate of the GDP has been $8 \%$, especially since the reforming and opening up in 1978 , it was up to $9.8 \%$. With the economic growth, the carbon dioxide emission increased continuously. Now, the China's carbon dioxide emission is over the United States to become the largest greenhouse gas emission country in the world. China always attach great importance to the sustainable development of environment and economy. With promulgation of "China's National Climate Change Programme" in June 4, 2007, the respective provincial administrative regions have started preparing climate change programs. Government at all levels have completed the preparation of programs to address climate change at the end of July 2009.

Heilongjiang which is a great resource and economic province of China has made a great progress of the social and economic development, since the reforming and opening up. The per capita GDP was increased from 2028 yuan in 1990 to 32819 yuan in 2011 and the per capita carbon emission from 1.08 tons to 1.77 tons. The economic grew in step with carbon emission in Heilongjiang province. With the rapid economic development, carbon emission and other environmental pollution problems restricted the sustainable economic development of Heilongjiang province in a certain extent. So, sustainable economic growth will be achieved facing with the climate and environmental pollution challenges, the effect of economic growth and carbon emission should be clarified[1,2]. In order to provide a reference for the industry and environment policies which is about developing the low-carbon economy of Heilongjiang province, this paper researched on the Environmental Kuznets Curve of carbon emission by investigating the dynamic relationship between the economic growth and carbon emission in Heilongjiang province during the period from 1980 to 2013. 


\section{Data sources and research methods}

Data sources. In order to be better to reflect the dynamic process, the per capita gross domestic product(GDP) was measured with fixed prices by using the 1990 for base period. GDP displayed the economic growth and was represented by PG. The per capita carbon emission displayed the carbon emission and was represented by PC. For lacking of the statistical data of carbon dioxide and the carbon emission mainly come from fossil fuels, this paper adopts the factors decomposition method to estimation the carbon emission. The method is shown in formula (1).

$$
\mathrm{C}_{\mathrm{it}}=\alpha \mathrm{C}_{\mathrm{jc}}+\beta \mathrm{C}_{\mathrm{jo}}+\gamma \mathrm{C}_{\mathrm{jg}}
$$

Among them, the $C_{i t}$ is the total carbon emission of Heilongjiang province, $C_{j c}$ is Heilongjiang's annual consumption of coal, $\mathrm{C}_{\mathrm{jo}}$ is annual consumption of oil for heilongjiang province, $\mathrm{C}_{\mathrm{jg}}$ is the annual consumption of natural gas in Heilongjiang province; $\alpha, \beta$ and $\gamma$ are the three kinds conversion coefficient of carbon emission when each kinds of fuels burning. The energy research institute of national development and reform commission published the three kinds conversion coefficient of carbon emission by the report of "2003 Study of the Sustainable Development of China's Energy and Carbon Emission Scenario Analysis". $\alpha, \beta$ and $\gamma$ are $0.7476,0.5825$ and 0.443 , respectively. The above data come from the "Heilongjiang Province Statistical Yearbook". At the same time, in order to eliminate the potential heteroscedasticity problems, and also to make the data can be compared in the same dimension, each of the index is logarithmic processing. The new sequence were named as $\ln \mathrm{PG}$ and $\ln \mathrm{PC}$, respectively.

Research methods. This research is analyzed by the general model of Environmental Kuznets Curve (EKC). The model is shown in equation(2).

$$
\mathrm{Y}=\mathrm{A}_{1} \mathrm{X}^{3}+\mathrm{A}_{2} \mathrm{X}^{2}+\mathrm{A}_{3} \mathrm{X}+\mathrm{B}+\varepsilon
$$

Among them, $\mathrm{Y}$ is $\ln \mathrm{PG}, \mathrm{X}$ is $\ln \mathrm{PC}, \mathrm{A}_{1}, \mathrm{~A}_{2}$ and $\mathrm{A}_{3}$ denote respectively the InPG of three times, secondary and primary coefficient, $B$ is a constant, $\varepsilon$ is a random error. To be specific, when $A_{1}=A_{2}=$ $\mathrm{A}_{3}=0$, there is no relationship between the per capita carbon emission and the per capita GDP; when $A_{1} \neq 0$, the relationship between the per capita carbon emission and the per capita GDP is present the $\mathrm{N}$-type or inverted N-type curve; when $\mathrm{A}_{2}<0$ and $\mathrm{A}_{1}=0$, there is an inverted U-shaped relationship between the per capita carbon emission and the per capita GDP; but when $A_{2}>0$ and $A_{1}=0$, there is a U-shaped relationship between the per capita carbon emission and the per capita GDP; when $A_{1}=0$, $A_{2}=0$ and $A_{3} \neq 0$, the per capita carbon emission is presenting monotonic change with the per capita GDP.

\section{Results and Discussion}

The dynamic relationship between the economic growth and carbon emission in Heilongjiang province. Fig. 1 is time series of economic growth and carbon dioxide emission in Heilongjiang province during 1990 to 2011. According to Fig. 1, carbon emission had always been to increase at a steady rate as economic growth.

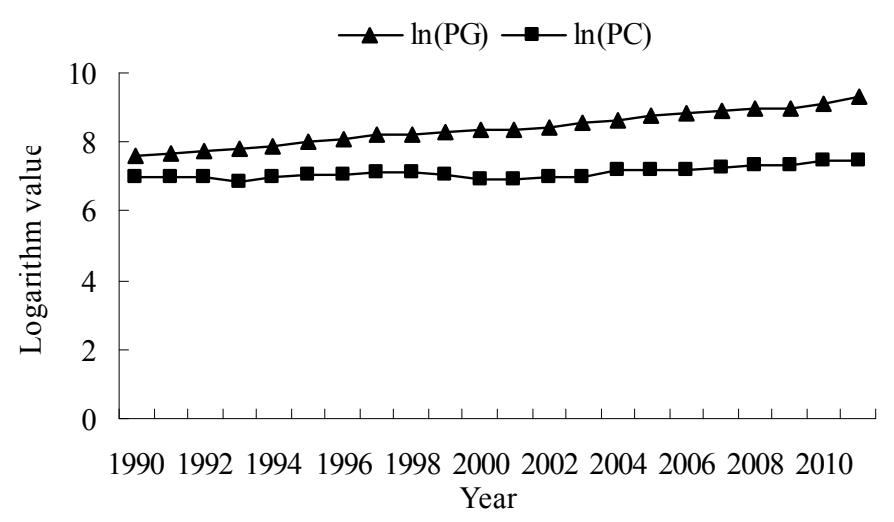

Fig. 1 Time series of $\ln \mathrm{PG}$ and $\ln \mathrm{PC}$ 
EKC of Carbon Emission Model. The relationship between InPG and InPC is simulated in this paper according to the linear equation model, quadratic equation model and cubic equation model respectively. Parameters of simulation are shown in table 1.

Table 1 Model Summary and Parameter Estimates

\begin{tabular}{|c|c|c|c|c|c|}
\hline Equations & $\mathrm{A}_{1}$ & $\mathrm{~A}_{2}$ & $\mathrm{~A}_{3}$ & B & $\mathrm{R}^{2}$ \\
\hline $\begin{array}{l}\text { Linear Equation } \\
\text { (including constant } \\
\text { term) }\end{array}$ & 0 & 0 & $0.297 * *$ & $4.615 * *$ & 0.725 \\
\hline $\begin{array}{c}\text { Linear Equation } \\
\text { (excluding constant } \\
\text { term) }\end{array}$ & 0 & 0 & $0.845^{* *}$ & 0 & 0.998 \\
\hline $\begin{array}{l}\text { Quadratic Equation } \\
\text { (including constant } \\
\text { term) }\end{array}$ & 0 & $0.255^{* *}$ & $-3.990 * *$ & $22.599 * *$ & 0.844 \\
\hline $\begin{array}{l}\text { Quadratic Equation } \\
\text { (excluding constant } \\
\text { term) }\end{array}$ & 0 & $-0.064 * *$ & $1.389 * *$ & 0 & 0.998 \\
\hline $\begin{array}{l}\text { Cubic Equation } \\
\text { (including constant } \\
\text { term) }\end{array}$ & $0.010 * *$ & 0.000 & $-1.845^{* *}$ & $16.590 * *$ & 0.844 \\
\hline $\begin{array}{c}\text { Cubic Equation } \\
\text { (excluding constant } \\
\text { term) }\end{array}$ & - & - & - & - & - \\
\hline
\end{tabular}

Quadratic equation model (excluding constant term) is best in simulation according to table 1 . Therefore, quadratic equation (excluding constant term) is selected to fit the relationship between per capita GDP and per capita carbon emission in this paper. The fitting equation between per capita GDP and per capita carbon emission is shown in equation(3).

$\ln \mathrm{PC}=-0.064 \mathrm{nPG}^{2}+1.389 \ln \mathrm{PG}$

According to the equation (3), EKC between per capita GDP and per capita carbon emission was structured out. The curve is shown in Fig. 2.

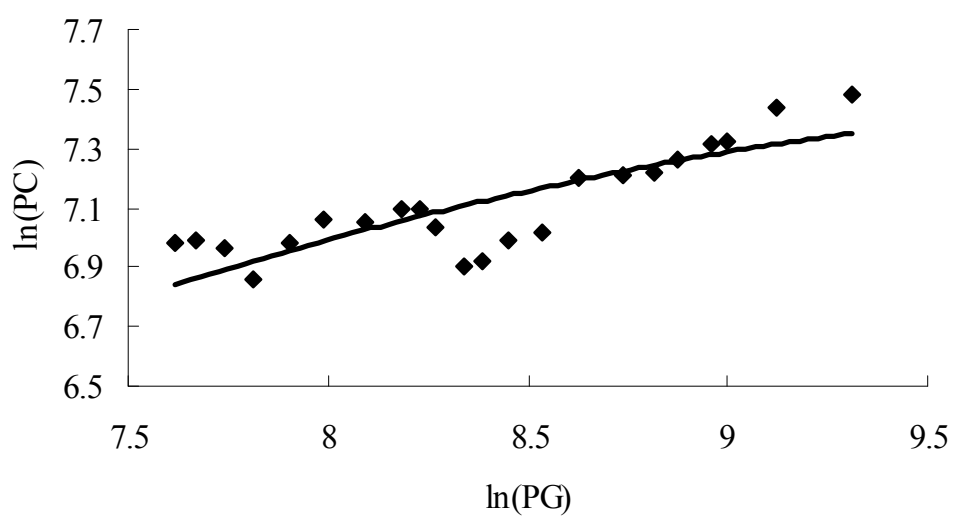

Fig. 2 Relationship Between per Capita GDP and per Capita Carbon Emission

According to the equation (3), per capita carbon emission shows inverted U-shaped relationship with per capita GDP, when the $\mathrm{A}_{2}<0$ and $\mathrm{A}_{1}=0$. It can also be seen from Fig.2, an inverted U-shaped relationship between China's per capita GDP and per capita carbon emissions It shows that the carbon 
emission of Heilongjiang province fits EKC. Meanwhile, we calculate the location of inflection point $\mathrm{x}=10.85$ according to the equation. This means that Heilongjiang province doesn't reach the position of the inflection point. If keeping the existing state, per capita carbon emission will increase gradually as the per capita GDP growth until the inflection point is arrival. Then, per capita carbon emission will decrease as the per capita GDP growth. This show that: with economic development, technical progress, government environmental policy and management to strengthen and enhance the environmental awareness of citizens will promote emissions reduction. Therefore, Heilongjiang province should accelerate technological innovation and develop feasible measures for energy saving to make sure Heilongjiang province through the inflection point as soon as possible.

\section{Conclusions}

The carbon emission increased at the same pace with economic growth in Heilongjiang province during 1990 to 2011. The relationship between economic growth and carbon emission accord with the inverted U-shaped of the Environmental Kuznets Curve, but now the carbon emission has not reached the inflection point. With the economic growth in the future, the carbon emission may further exacerbated. In order to realize the energy conservation and emission reduction and the sustainable development of low-carbon economy, Heilongjiang province must accelerate technological innovation, readjust industrial structure and actively promote the development and implementation of energy conservation policy.

\section{Acknowledgements}

This work was financially supported by Heilongjiang Postdoctoral Science-Research Foundation (No. LBH-Q13101) and the Program for Young Academic Backbone of Harbin Normal University (No. 10KXQ-08).

\section{Literature References}

[1] A. Jalil and S.F. Mahmud: Environment Kuznets curve for $\mathrm{CO}_{2}$ emissions: A cointegration analysis for China, Energy Policy Vol. 37(2009), p.5167.

[2] L. Taedong and V. M. Susan: Comparative studies of urban climate co-benefits in Asian cities: an analysis of relationships between $\mathrm{CO}_{2}$ emissions and environmental indicators, Journal of Cleaner Production Vol.58(2013), p.15. 